\title{
Current concepts in the management of clavicle fractures
}

\author{
Robert Moverley ${ }^{a,{ }^{*}}$, Nick Little ${ }^{\mathrm{b}}$, Abhinav Gulihar ${ }^{\mathrm{c}}$, Bijayendra Singh ${ }^{\mathrm{d}}$ \\ a Guy's \& St Thomas's Hospital, London, UK \\ ${ }^{\mathrm{b}}$ Epsom \& St Helier Hospitals NHS Trust, London, UK \\ ${ }^{c}$ Princess Royal University Hospital, London, UK \\ ${ }^{\mathrm{d}}$ Medway Martime Hopsital, London, UK
}

\section{A R T I C L E I N F O}

\section{Article history:}

Received 15 April 2019

Received in revised form

23 July 2019

Accepted 24 July 2019

Available online 24 July 2019

\section{Keywords:}

Clavicle fracture

Lateral clavicle

Clavicle non-union

\begin{abstract}
A B S T R A C T
Clavicle fractures comprise approximately 3\% of all adult fractures and there is evidence that the incidence is increasing. Fractures of the lateral and middle third of the clavicle present distinct challenges in both surgical fixation techniques and clinical outcome, as such they should be recognised as separate clinical entities. Despite conflicting evidence, most studies indicate that superior clinical results are found in patients with united clavicle fractures rather than those that go onto non-union. Furthermore there is level-1 evidence that operative treatment of clavicle fractures leads to significantly increased rates of union. Despite these findings, significant controversy still exists on which patients would benefit from primary fixation and those who could successfully be managed non-operatively. We present an evidence-based review of clavicle fracture management including surgical indications, techniques, and results.
\end{abstract}

\section{Introduction}

The clavicle a double-curved S shaped bone. It is unique as the only long bone in the human body that lies horizontally. Its primary function is to act a strut for the scapula to suspend the upper limb away from the thorax thus allowing the extensive range of movement that the upper limb exhibits. The clavicle is a commonly fractured bone comprising $2.6-4 \%$ of all adult fractures. ${ }^{1,2}$ Swedish fracture registry data shows that clavicle fracture incidence has almost doubled from 35.6 to 59.3 per 100,000 between 2001 and 2012. ${ }^{3}$ There is a bimodal distribution of adult clavicle fractures with increased incidence in males under 30 years of age, usually due to high energy trauma and a second peak in the elderly population due to osteoporosis which are usually associated with low energy falls. Young adults tend to fracture the mid-shaft of the clavicle whereas in the elderly the lateral end of the clavicle is more commonly involved.

\subsection{Classification}

Traditionally clavicle fractures have been classified based on the

\footnotetext{
* Corresponding author.

E-mail address: robert.moverley@doctors.org.uk (R. Moverley).
}

anatomical location. Type I fractures occur within the middle third of the clavicle, whereas type II and type III fractures occur in the lateral and medial thirds, respectively. ${ }^{4}$ Neer described a sub classification (modified by Craig) for lateral clavicle fractures based on displacement of the fracture and the involvement of the coracoclavicular ligaments (Fig. 1). According to the Neer classification types III and I are considered stable whereas types II IV and V are unstable.

Robinson has proposed a universal classification system ${ }^{1}$ (Fig. 2), once again the fracture is classified on anatomical location with further subtypes based on the fracture fragments and displacement. Fractures with displacement of less than $100 \%$ comprise subgroup A with those displaced greater than $100 \%$ accounting for subgroup B. Medial and lateral fractures are further subdivided based on intra-articular extension. Middle third fractures are subcategorized by the degree of fracture comminution and pattern. Simple or wedge-type fracture patterns make up subgroup 1, whereas comminuted or segmental fracture comprise subgroup 2. ${ }^{1}$ Whilst these classification systems have proven useful, neither classification system provides guidance on which treatment mode would be most appropriate, or prognostic value for each unstable subtype. ${ }^{5,6}$

This review will focus on the management of middle and lateral third clavicle fractures. 


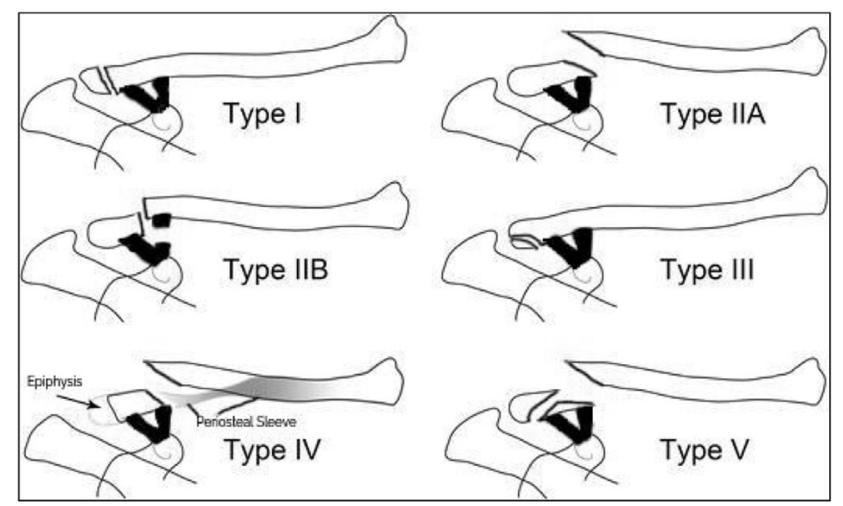

Fig. 1. Schematic diagram of the Neer (modified by Craig) classification of lateral clavicle fractures.

\section{Lateral clavicle fractures}

Approximately $15 \%$ of clavicle fractures occur within the lateral third of the bone. ${ }^{3}$ Good clinical outcomes have been achieved with non-operative management of undisplaced fractures whereas displaced fractures are associated with a non-union rates between 18 and $43 \%{ }^{7,8}$ In the largest series of non-operatively managed displaced lateral clavicle fractures $14 \%$ of patients required surgery for non-union or symptomatic mal-union. ${ }^{9}$ No consensus exists on which fracture and patient groups require surgical fixation. Most surgeons advocate a patient specific approach considering factors such as age, activity level, and general health status. The surgical complications of clavicle surgery fixation must also be considered which include but are not limited to; infection, vascular injury, nerve damage, non-union, symptomatic hardware and even death. The true incidence of complications is unknown, however a recent systematic review suggests the overall complication rate is at least $9 \%{ }^{10}$

\subsection{Fixation techniques}

Once a decision to operate has been made the surgeon is presented with choice of techniques that can be utilised. These have traditionally included intramedullary devices, hook plates, K-wires, locked anatomical contoured plates fixation, coracoclavicular (CC) stabilisation using a suspensory device or screw, or a combination of the above. Hook plate or anatomical plate fixation requires only a superior approach to the clavicle; many surgeons may therefore find this preferable to CC stabilisation, which also requires exposure of the coracoid.

A systematic review of several techniques used in 425 fractures showed similar non-union rates between methods (1.6\%) but unacceptably high complication rates were noted in those treated with a hook plate $(40.7 \%)$ or tension band wire $(20.0 \%)$ (Table 1$).^{11}$ Good clinical results have been reported with CC screw fixation but as with $\mathrm{K}$-wires and hook plates a second operation to remove the metalwork is mandated. ${ }^{12}$

\subsection{Coracoclavicular stabilization}

Recent strategies have focussed on the use of a low profile locking plate and CC stabilization using a suspensory device such as a Tightrope ${ }^{\circledR}$. These have been shown to have good results and do not mandate a second operation for implant removal. ${ }^{13}$

The position of the primary fracture lines and the integrity of the CC ligaments can guide the surgeon to choose appropriate fixation techniques for individual fracture patterns.

If the fracture is medial to the coracoid it is unlikely that the CC ligaments are involved and the operative mode of fixation can be a plate alone, used in the same mode as when fixing a middle third clavicle fracture (Fig. 3a). If the primary fracture line is within the width of the coracoid base it is likely that the coracoclavicular ligaments are compromised, the mode of fixation should consist of a suspensory device, which can be augmented with a plate if the superior cortex is found to be comminuted or without enough bone to provide sufficient resistance to a suspensory device (Fig. 3b). This can either be predicted pre-operatively from the radiographs or an assessment made intra-operatively. If the fracture is lateral to the coracoid base and displaced it is likely that the CC ligaments are involved. Suspensory fixation will be required but it is likely that the addition of a plate will add little or nothing to the stability of the fixation as the purchase of screws in the far lateral end of the clavicle is likely to be minimal and risks acromioclavicular joint penetration with the screws. Therefore, the mode of fixation can be a suspensory device only (Fig. 3c). This potentially allows for a shorter operation through a smaller incision and theoretically, a reduced need for implant removal. A suspensory device can also be implanted arthroscopically, which has a proven track record in the literature. $^{14}$

A recent prospective study by Beirere showed that surgery in patients with Neer IIb fractures using a low profile contoured plate without suspensory fixation had significantly lower Taft scores (indicating acromioclavicular joint instability) than other fracture patterns where the cc ligaments were intact. This supports the use of coracoclavicular fixation in this group of patients. ${ }^{13}$

\section{Middle third fractures}

Historically the majority of middle third clavicle fractures were managed non-operatively, largely due to two large case series in the 1960 by Neer and Rowe which demonstrated non-union rates of less than $1 \% .{ }^{4,7}$ This figure has been heavily criticised as it contains data from paediatric patients in whom non-union is extremely rare. Subsequent studies have failed to reproduce such low non-union rate and suggest the true non-union rate is $7-15 \%{ }^{15-18}$ Simply achieving union of the clavicle does not guarantee a good clinical outcome as displaced fractures inevitably heal with some degree of malunion due to either angulation or shortening or a combination thereof. $^{19}$

The clinical significance of clavicle shortening has received particular attention because of the biomechanical principle that the moment arm of the shoulder girdle muscles will be altered, potentially leading to increased fatigability and impaired shoulder function. However the evidence for this has been conflicting. Multiple retrospective reviews of non-operatively managed midshaft fractures showed that initial shortening of $>2 \mathrm{~cm}$ was associated with a poor clinical outcome. ${ }^{15,20}$ This was further evidenced by a clinical and CT study showing that greater than $1.5 \mathrm{~cm}$ of final shortening was associated with weaker muscle strength and poorer shoulder scores than the uninjured arm. ${ }^{21}$ However a more recent systematic review with has concluded that shortening alone is not an evidence-based indication to operate for the goal of functional improvement. ${ }^{22}$ It should be noted that in this study a pooled analysis of data could not be performed due to wide heterogeneity of the data between studies.

\subsection{Multicentre RCT}

In an effort to provide definitive answers on the optimum management for displaced mid-shaft clavicle fractures several prospective randomised controlled trials have been carried out 


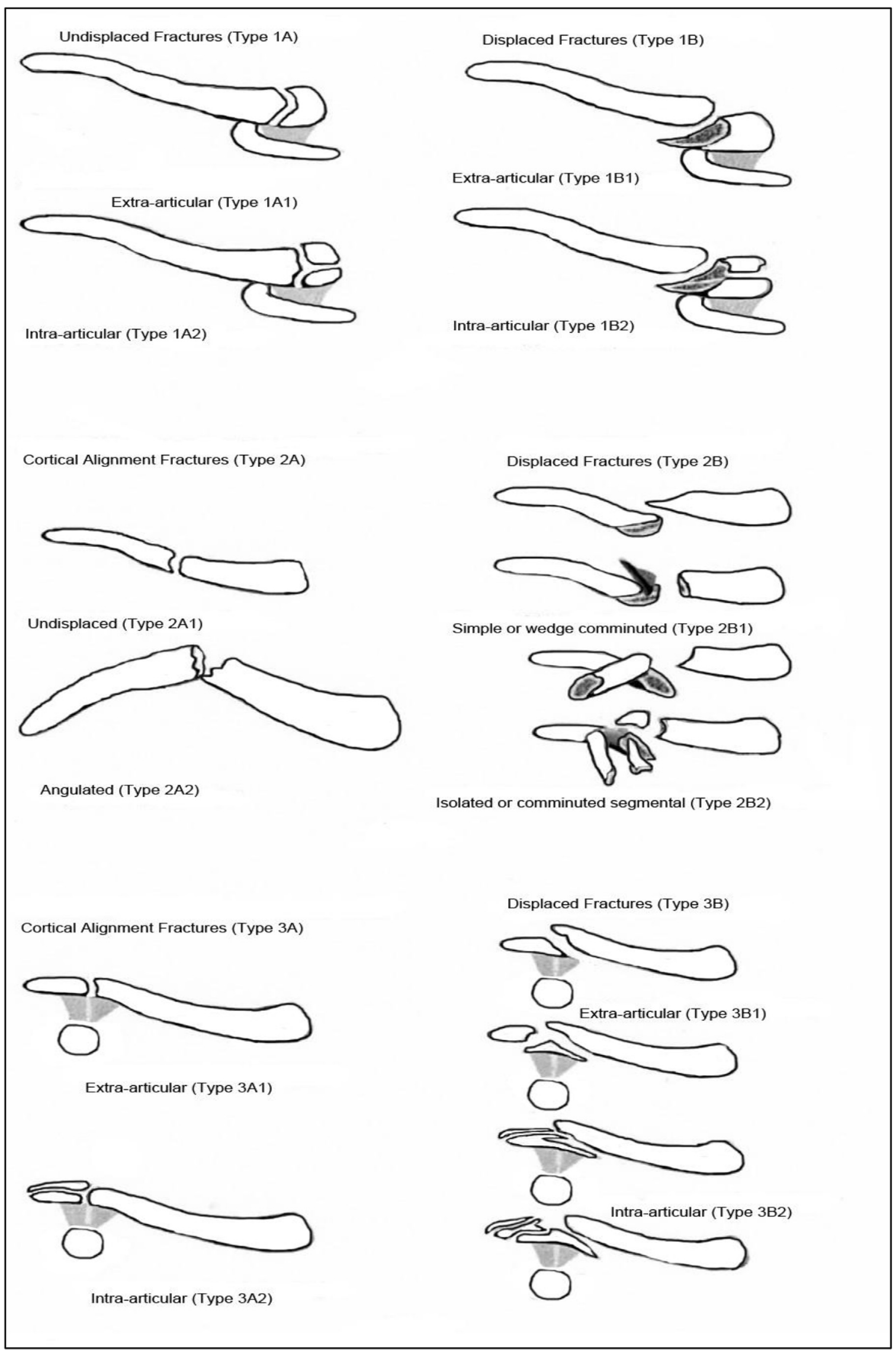

Fig. 2. Universal classification system of clavicle fractures (Robinson et al. ${ }^{1}$ ). 
Table 1

Common complications of lateral clavicle fixation. ${ }^{1}$

\begin{tabular}{ll}
\hline Fixation method & Common complications \\
\hline Hook Plate & Impingement in motion Plate Migration Acromion osteolysis \\
K-Wire plus TBW & Infection Loss of reduction \\
CC Screw & Screw back out \\
\hline
\end{tabular}

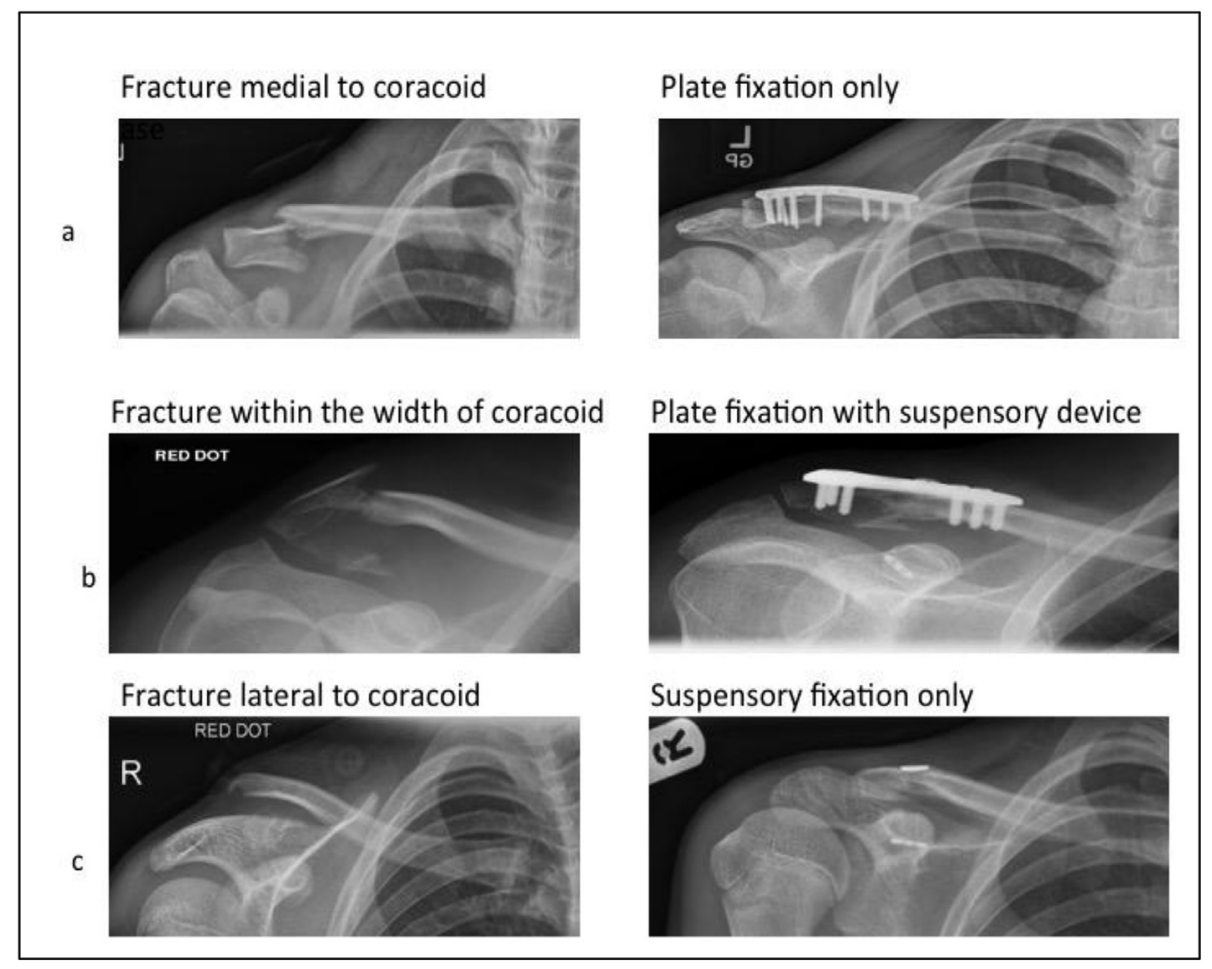

Fig. 3. Combination of fixation methods for lateral clavicle fractures depending on the location of the fracture in relation to the coracoid.

comparing primary operative with non-operative treatment. Interestingly the three largest studies have produced similar results but the authors have drawn differing conclusions. ${ }^{17,23,24}$ All three studies defined displaced fractures as having no cortical contact between the main fragments and operative management consisted an anatomically contoured plate and screw fixation.

The COTS study enrolled 132 patients and reported better significantly outcomes in the operative group (higher Constant scores and lower Disability of the Arm, Shoulder \& Hand (DASH) scores) at all time points between 6 and 52 weeks. They also reported significantly higher rates of non-union and symptomatic malunion non-operative group. Patients were also more likely to be satisfied with the appearance of the shoulder in the operative group with only $3 / 62$ patients unhappy at the appearance of the scar versus 10/49 in the non-operative group dissatisfied with a "droopy shoulder". The overall conclusion of the study was to advocate primary plate fixation for displaced midshaft fractures in active adults. $^{24}$

Robinson et al. postulated that the superior results shown in the COTS trial might have been due to a small number of patients in the non-operative group who had poor outcomes due to non-union. ${ }^{17}$ They carried out a prospective study similar in design to the COTS trial, which again demonstrated higher rates of symptomatic nonunion in the non-operative group ( $17 \%$ Vs. $1 \% \mathrm{p}=0.007)$. The number needed to treat (NNT) was 6.2 to prevent one case of nonunion. All of the non-union patients who elected to undergo subsequent surgery $(n=13)$ went on to achieve union. Non-operative treatment and smoking were the only two independent variables associated with non-union. Functional outcomes were better in the operative group at all time points with the exception of the Constant score at six weeks and six months and the DASH score at six months. When the non-union patients were excluded there were no significant differences at any time point in the Constant or DASH between groups. The development of non-union was the only factor that was independently associated with poorer functional outcome. The complication rate in the operative group (including removal of hardware) was $19 \%$ (16/86). There was no evidence of earlier return to work and sporting activity in the operative group. The study concluded that there is insufficient evidence to support the routine operative treatment for displaced clavicle fractures and that future work is needed to allow identification of the subgroup that would benefit.

'The Clavicle Trial' which reported in 2017, once again demonstrated improved early functional scores in patients undergoing primary operative fixation (six weeks and three months) but at nine months there were no significant differences between groups. ${ }^{23}$ Similar non-union rates to previous trials were found. The authors concluded that the results of a united clavicle fracture is good, regardless of treatment modality and that surgery should be offered to patients with displaced mid-shaft clavicle fractures. ${ }^{23}$

Homogeneity in both trial methods and data has led to the publication of a meta-analysis, the pooled results of which can be useful when counselling patients of their treatment options (Table 2). ${ }^{25}$ This study also reported that the patients with a non- 
Table 2

Pooled results for plate fixation versus non-operative treatment. ${ }^{25}$

\begin{tabular}{|c|c|c|c|}
\hline & Plate fixation & Non-Operative & \\
\hline Non-union & $1.9 \%$ & $16.5 \%$ & $\mathrm{RR}(\mathrm{CI}) 0.14(0.06-0.32)^{*}$ \\
\hline Operation for Non-union & $1.3 \%$ & $10.9 \%$ & $\mathrm{RR}(\mathrm{CI}) 0.13(0.05-0.31)^{*}$ \\
\hline Overall Secondary operations & $17.6 \%$ & $16.6 \%$ & $\mathrm{RR}(\mathrm{CI}) 1.01(0.64-1.59)^{*}$ \\
\hline Constant score 1 year** & 89.4 & 82.5 & Mean Difference (CI) 4.39(0.70-7.87) \\
\hline DASH score 1 year** & 4.5 & 3.2 & Mean Difference $(\mathrm{CI})-5.07(-10.08$ to -0.06$)$ \\
\hline
\end{tabular}

${ }^{*} \mathrm{P}<0.05,{ }^{* *}$ Includes patients with non-union.

union who were yet to receive surgery had a lower functional score than the patients who had achieved union: mean Constant scores were $86.2(\mathrm{SD}=11.7)$ and $96.3(\mathrm{SD}=6.7)(\mathrm{p}=0.01)$, and mean DASH scores were $14.7(\mathrm{SD}=14.6)$ and $3.3(\mathrm{SD}=6.1)(\mathrm{p}=0.005)$, respectively.

It is clear from the published evidence that good clinical outcomes can be achieved with both operative and non-operative treatment. We advocate a patient centred approach i.e. a patient should be provided with sufficient information in order to make an informed decision specific to their needs. We therefore counsel patient that the choice is theirs to make but the relevant information is that the fracture is more likely to heal with surgery and the early outcome may be better but this effect diminishes within a year. The 'price tag' of surgery is the risk of complications, which may include the need for another operation to remove the plate or rare but more serious complications including deep infection and permanent nerve damage.

\subsection{Non-union}

If non-operative treatment is chosen and the fracture fails to heal then surgery is an option, which usually leads to good clinical outcomes and functional scores similar to primary fixation. ${ }^{25-27}$ These figures should be interpreted with caution as they are based on small retrospective series.

Given that united fractures tend to do well it would be appealing to identify a way of identifying those patients who may go on to non-union. Unfortunately no reliable system exists. A systematic review by Jorgensen showed that the usual suspects of smoking, age, displacement and comminution could be associated with nonunion $^{28}$ (Table 3). Although it should be noted that for each potential predictor of non-union at least one study did not find any association - including smoking. A study examining non-union following plate fixation showed that smoking was the only identifiable risk factor to increase failure rates. We advocate counseling patients with respect to this and where necessary facilitating referral to smoking cessation services. ${ }^{29}$

\subsection{Cost effectiveness}

The cost effectiveness of clavicle fixation is a controversial topic largely because the long term duration of benefit related to ORIF vs. non-operative treatment is unknown. Several authors have

Table 3

Risk factors for non-union. ${ }^{28}$

\begin{tabular}{ll}
\hline Factors shown to be a risk (odds ratios) & Factors NOT shown to be a risk \\
\hline Smoking (3.76) & Fracture shortening \\
Complete Displacement (1.17) & Vertical fragment \\
Comminution (2.32) & Angulation \\
Increased Age (1.01) & Translation \\
Female (1.43) & Associated injuries \\
& Mechanism of injury \\
& Occupation \\
\hline
\end{tabular}

attempted to analyze the cost effectiveness in terms of quality of life adjusted years (QALYs) gained. Pearson et al. suggest a basecase cost per QALY gained for ORIF was USD 65,000, which is below the widely accepted USD 50,000/QALY cost effectiveness threshold. This study suggests that the benefits of surgery would need to persist for 9.3 years or more to reach the cost effectiveness threshold. ${ }^{30}$ Whilst the majority of cost effectiveness studies have focused on the costs to the healthcare provider, Althausen et al. have attempted the associated costs to the patients. They found that operative patients missed fewer days from work (8.4 Vs. 35.2) and less loss of income (USD 321.69 Vs. USD 10,506.25). ${ }^{31}$ This should be considered in the decision making process when managing these patients and may be of particular relevance to selfemployed or manual workers.

\section{Conclusions}

Distal and mid-shaft clavicle fractures should be considered separate clinical entities. Surgical fixation or conservative treatment is a viable for most displaced fractures and patients should be given adequate information to make a decision, which is right for them. The Mechanism of injury, vertical fragment and shortening may not be an independent factor - but is likely to co-exist with displacement and degree of comminution and therefore might reasonably be included in the decision making process. It is also reasonable to surmise that younger, active patients or manual workers with displaced fractures may benefit from early surgery.

Overall advocate a patient specific approach to treating these injuries based on fracture pattern, co-morbidity and patient expectations. Smoking is an independent risk factor for non-union in both operative and non-operative treatments and patients should be informed of this in order to improve their final clinical outcome.

\section{Declarations of interest}

None.

\section{Conflicts of interest}

I certify that there is no conflict of interest with the authors of this manuscript regarding the material discussed in the manuscript.

\section{Funding}

This research did not receive any specific grant from funding agencies in the public, commercial, or not-for-profit sectors.

\section{Appendix A. Supplementary data}

Supplementary data to this article can be found online at https://doi.org/10.1016/j.jcot.2019.07.016. 


\section{References}

1. Robinson CM. Fractures of the clavicle in the adult. Epidemiology and classification. J Bone Joint Surg Br. 1998;80(3):476-484.

2. Nordqvist A, Petersson C, Redlund-Johnell I. The natural course of lateral clavicle fracture. 15 (11-21) year follow-up of 110 cases. Acta Orthop Scand. 1993;64(1):87-91. http://www.ncbi.nlm.nih.gov/pubmed/8451958. Accessed October 7, 2018.

3. Huttunen TT, Launonen AP, Berg HE, Lepola V, Felländer-Tsai L, Mattila VM. Trends in the incidence of clavicle fractures and surgical repair in Sweden: 2001-2012. J Bone Jt Surg - Am. 2016;98(21):1837-1842. https://doi.org/ 10.2106/JBJS.15.01284.

4. Allman FL. Fractures and ligamentous injuries of the clavicle and its articulation. J Bone Joint Surg Am. 1967;49(4):774-784. http://www.ncbi.nlm.nih.gov/ pubmed/6026010. Accessed October 7, 2018.

5. Cho $\mathrm{CH}$, Oh JH, Jung $\mathrm{GH}$, et al. The interrater and intrarater agreement of a modified neer classification system and associated treatment choice for lateral clavicle fractures. Am J Sports Med. 2015;43(10):2431-2436. https://doi.org/ 10.1177/0363546515593949.

6. Bishop JY, Jones GL, Lewis B, Pedroza A. Intra- and interobserver agreement in the classification and treatment of distal third clavicle fractures. Am J Sports Med. 2015;43(4):979-984. https://doi.org/10.1177/0363546514563281.

7. Neer CS. Fractures of the distal third of the clavicle. Clin Orthop Relat Res. 1968;58:43-50. http://www.ncbi.nlm.nih.gov/pubmed/5666866. Accessed October 7, 2018.

8. Kona J, Bosse MJ, Staeheli JW, Rosseau RL. Type II distal clavicle fractures: a retrospective review of surgical treatment. J Orthop Trauma. 1990;4(2): 115-120. http://www.ncbi.nlm.nih.gov/pubmed/2358923. Accessed October 7, 2018.

9. R CM, C DA. Primary nonoperative treatment of displaced lateral fractures of the clavicle. J Bone Jt Surg - Ser A. 2004;84(4):778-782.

10. Wijdicks FJG, Millett PJ, Houwert RM, Van Der Meijden OAJ, Verleisdonk EJMM. Systematic review of the complications of plate fixation of clavicle fractures. Arch Orthop Trauma Surg. 2012. https://doi.org/10.1007/s00402-011-1456-5.

11. Oh JH, Kim SH, Lee JH, Shin SH, Gong HS. Treatment of distal clavicle fracture: a systematic review of treatment modalities in 425 fractures. Arch Orthop Trauma Surg. 2011;131(4):525-533. https://doi.org/10.1007/s00402-0101196-y.

12. Fazal M, Saksena J, Haddad F. Temporary coracoclavicular screw fixation for displaced distal clavicle fractures. J Orthop Surg. 2007;15(1):9-11. https:// doi.org/10.1177/230949900701500103.

13. Beirer $M$, Siebenlist $S$, Crönlein $M$, et al. Clinical and radiological outcome following treatment of displaced lateral clavicle fractures using a locking compression plate with lateral extension: a prospective study. BMC Muscoskelet Disord. 2014;15:380. https://doi.org/10.1186/1471-2474-15-380.

14. Checchia SL, Doneux PS, Miyazaki AN, Fregoneze M, Silva LA. Treatment of distal clavicle fractures using an arthroscopic technique. J Shoulder Elb Surg. 2008;17(3):395-398. https://doi.org/10.1016/j.jse.2007.08.011.

15. Hill JM, McGuire MH, Crosby LA. Closed treatment of displaced middle-third fractures of the clavicle gives poor results. J Bone Jt Surg. 1997;79(4): 537-539. https://doi.org/10.1302/0301-620X.79B4.7529.

16. Nowak J, Holgersson M, Larsson S. Can we predict long-term sequelae after fractures of the clavicle based on initial findings? A prospective study with nine to ten years of follow-up. J Shoulder Elb Surg. 13(5):479-486. doi:10.1016 S1058274604000436.

17. Robinson C, Goudie E, Murray I, et al. Open reduction and plate fixation versus nonoperative treatment for displaced midshaft clavicular fractures. $J$ Bone $J$ Surgery-American. 2013;95(17):1576-1584. https://doi.org/10.2106/ JBJS.L.00307.

18. Gossard JM. Closed treatment of displaced middle-third fractures of the clavicle gives poor results. J Bone Joint Surg Br. 1998;80(3):558. http://www.ncbi.nlm. nih.gov/pubmed/9619962. Accessed October 10, 2018.

19. Edelson JG. The bony anatomy of clavicular malunions. J Shoulder Elb Surg. 2003;12(2):173-178. https://doi.org/10.1067/mse.2003.2.

20. Wick M, Müller EJ, Kollig E, Muhr G. Midshaft fractures of the clavicle with a shortening of more than $2 \mathrm{~cm}$ predispose to nonunion. Arch Orthop Trauma Surg. 2001;121(4):207-211. http://www.ncbi.nlm.nih.gov/pubmed/11317682. Accessed October 10, 2018.

21. Ledger M, Leeks N, Ackland T, Wang A. Short malunions of the clavicle: an anatomic and functional study. J Shoulder Elb Surg. 2005;14(4):349-354. https://doi.org/10.1016/j.jse.2004.09.011.

22. Woltz S, Sengab A, Krijnen P, Schipper IB. Does clavicular shortening after nonoperative treatment of midshaft fractures affect shoulder function? A systematic review. Arch Orthop Trauma Surg. 2017;137(8):1047-1053. https:// doi.org/10.1007/s00402-017-2734-7.

23. Ahrens PM, Garlick NI, Barber J, Tims EM. The clavicle trial. J Bone Jt Surg - Am. 2017;99(16):1345-1354. https://doi.org/10.2106/JBJS.16.01112.

24. Canadian Orthopaedic Trauma Society. Nonoperative treatment compared with plate fixation of displaced midshaft clavicular fractures. J Bone Jt Surg. 2007;89(1):1-10. https://doi.org/10.2106/JBJS.F.00020.

25. Woltz S, Krijnen P, Schipper IB. plate fixation versus nonoperative treatment for displaced midshaft clavicular fractures. J Bone Jt Surg. 2017;99(12): 1051-1057. https://doi.org/10.2106/JBJS.16.01068.

26. Das A, Rollins KE, Elliott K, et al. Early versus delayed operative intervention in displaced clavicle fractures. J Orthop Trauma. 2014;28(3):119-123. https:/ doi.org/10.1097/BOT.0b013e3182a2968e.

27. Faraud A, Bonnevialle N, Allavena C, Nouaille Degorce $H$, Bonnevialle $P$ Mansat P. Outcomes from surgical treatment of middle-third clavicle fractures non-union in adults: a series of 21 cases. Orthop Traumatol Surg Res. 2014;100(2):175-180. https://doi.org/10.1016/J.OTSR.2013.09.011.

28. Jørgensen A, Troelsen A, Ban I. Predictors associated with nonunion and symptomatic malunion following non-operative treatment of displaced midshaft clavicle fractures - a systematic review of the literature. Int Orthop. 2014;38(12):2543-2549. https://doi.org/10.1007/s00264-014-2450-7.

29. Jarvis NE, Halliday L, Sinnott M, Mackenzie T, Funk L, Monga P. Surgery for the fractured clavicle: factors predicting nonunion. J Shoulder Elb Surg. 2018;27(5): e155-e159. https://doi.org/10.1016/j.jse.2017.10.010.

30. Pearson AM, Tosteson ANA, Koval KJ, et al. Is surgery for displaced, midshaft clavicle fractures in adults cost-effective? Results based on a multicenter randomized, controlled trial. J Orthop Trauma. 2010. https://doi.org/10.1097/ BOT.0b013e3181c3e505.

31. Althausen PL, Shannon S, Lu M, O'Mara TJ, Bray TJ. Clinical and financial comparison of operative and nonoperative treatment of displaced clavicle fractures. J Shoulder Elb Surg. 2013. https://doi.org/10.1016/j.jse.2012.06.006. 